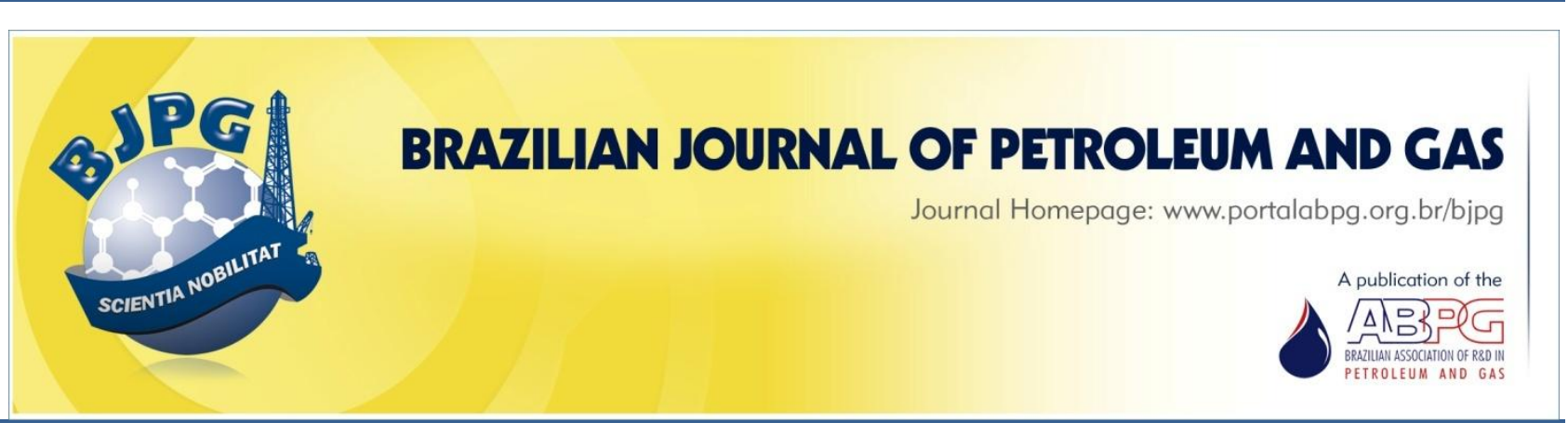

\title{
MATHEMATICAL MODELING OF AN AIRLIFT FLOTATION COLUMN WITH DIFFERENT GEOMETRIES FOR WATER AND OIL SEPARATION
}

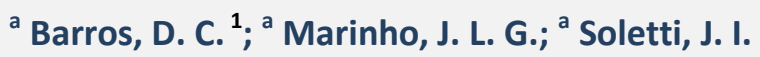 \\ a Federal University of Alagoas, Chemical Engineering Program, Maceió - Alagoas, Brazil.
}

\begin{abstract}
Petroleum is one of the top commodities in the world, which produces some of the most environmentally hazardous wastes, such as produced water. Thus, research on technologies capable of processing wastewater are important for promoting the treatment of this waste and reducing costs in the segment. Among the processes used to treat wastewater, flotation is one of the leading methods used in physical separation operations. The efficiency of this technique has a high influence on internal hydrodynamic flows. This paper proposes a mathematical modeling to fluid dynamics of oil-water separation in an airlift flotation column based on momentum and continuity balance equations. To simplify the modeling used, we considered only the drag force as the most relevant interfacial force in this phenomenon. The software Ansys CFX 13.0 was used to evaluate the data. Three columns were created, and all data were submitted to a simulated effluent, containing $1000 \mathrm{ppm}$ of oil. By evaluating efficiency selection in three columns and observing the countercurrent design, we found $84.72 \%$ as the best result achieved. This result can be associated with a column model that allows better phase contact as an ideal turbulence in the recirculation zone. Despite the simplifications in the proposed model, it is possible to observe a good association between the results obtained in the simulations and the ones presented in the literature.
\end{abstract}

\section{KEYWORDS}

fluid dynamics computing; flotation; airlift; simulation; difference geometry

\footnotetext{
${ }^{1}$ To whom all correspondence should be addressed.

Address: Federal University of Alagoas, Technology Center, Chemical Engineering Program, Campus A.C.Simões, Maceió-AL, Brazil.

ZIP Code: 57072-970| Phone number: +55(82)3214-1276 | e-mail: dcbarros1@gmail.com

doi:10.5419/bjpg2020-0006
} 


\section{INTRODUCTION}

Water is a raw material used in various manufacturing processes. In the petroleum sector, after its use, water separated from oil becomes a waste or effluent and must be treated properly to comply with current legislation (Thompson, 2015). The main destinations for the industrial effluents of the petroleum industry, after proper treatment, are reuse or disposal.

The flotation process is a type of effluent treatment which consists in the coalescence of the effluent by the action of bubbles gas inside the columns. This process stands out, generating a more concentrated profile with the effluent at the top of the equipment and a less concentrated profile at the base (Yu et al., 2017).

The hydrodynamics in the flotation column can improve the contact between the phases, generating better efficiencies or material savings (Rajak et al., 2015). Thus, literature proposes that there are different column geometries developed to promote best contact between the gas and liquid phases, such as the airlift flotation columns and multi-stage baffle columns.

He at al. (1995) studied a multi-stage flotation system divided by regions in the inner tube that forced the external flow to recirculate within them. These regions were called recirculation stage promoted a better collision between the dispersed phases, oil, and air. The authors observed the influences of different stages of recirculation, observing a better removal with the addition of more stages of recirculation in the column. Another point evaluated by the authors was the improvement of oil removal using $\mathrm{CO}_{2}$ as a carrier gas. The decrease in the $\mathrm{pH}$ generated by the use of this fluid in the medium reduced the repulsion between oil droplets and gas bubbles, removing over $90 \%$ of the oil using $\mathrm{CO}_{2}$.

Gu and Chiang (1999), like He at al. (1995), developed a similarly shaped column using common air as a gas. The addition of baffles allowed the creation of a low-pressure zone in the regions between recirculation stages, allowing a longer residence time. From the bubbles in the column, using air as a carrier gas and further stages of recirculation, 90 - 93\% separation of light emulsions was achieved.

In Qi et al. (2013), an airlift flotation column was used in the separation of oil in effluents from the petroleum industry. The effluent feed was countercurrent with the flow of bubbles. This column has only one central duct with the recirculation region occurring at the bottom of the column. For the equipment studied, the optimal separation was achieved in a gas flow between 10 $15 \mathrm{~m}^{3} /\left(\mathrm{hm}^{3}\right)$, decreasing in larger flows due to the high air concentration and turbulence in this phase, making the contact between the phases difficult. A separation efficiency of $89.3 \%$ oil removal was observed without the use of chemicals for an initial concentration of $449.1 \mathrm{ppm}$ oil in the effluent.

Marinho (2015) compared, using the common method, the multistage airlift flotation column profiles with uniform bubble distribution in the column with the most uniform airlift configuration. As a result, a better effluent separation was inferred for this column profile with $83 \%$ of separation efficiency.

Another major factor in this study was the nonuse of chemicals, which allowed a lower cost of operation. Another point evaluated by the author was the positive influence on oil removal, through the combined actions between dilution and effluent flow variables together with the effluent concentration of oil with air bubbles in the medium, achieving efficiency greater than $80 \%$.

Another model used for wastewater treatment is the airlift reactor, which is a special case of a bubbling column. The difference in air between reactor regions allows the recirculation of the liquid inside the column, increasing the residence time of the air bubbles (Ammar \& Akbar, 2018).

Thus, the present study intends to evaluate different geometries based on Marinho's airlift flotation column (Marinho, 2015), aiming to find the geometry that provides better water-oil separation efficiency. This study will be performed through computational analysis using the Ansys CFX 13.0 software.

\section{MATERIALS AND METHODS}

\subsection{Geometry and mesh}

The geometric analysis considered the column proposed by Marinho (2015) based on the airlift phenomenon, generating three columns for the present study. The geometries were generated by Ansys Spaceclaim software. 


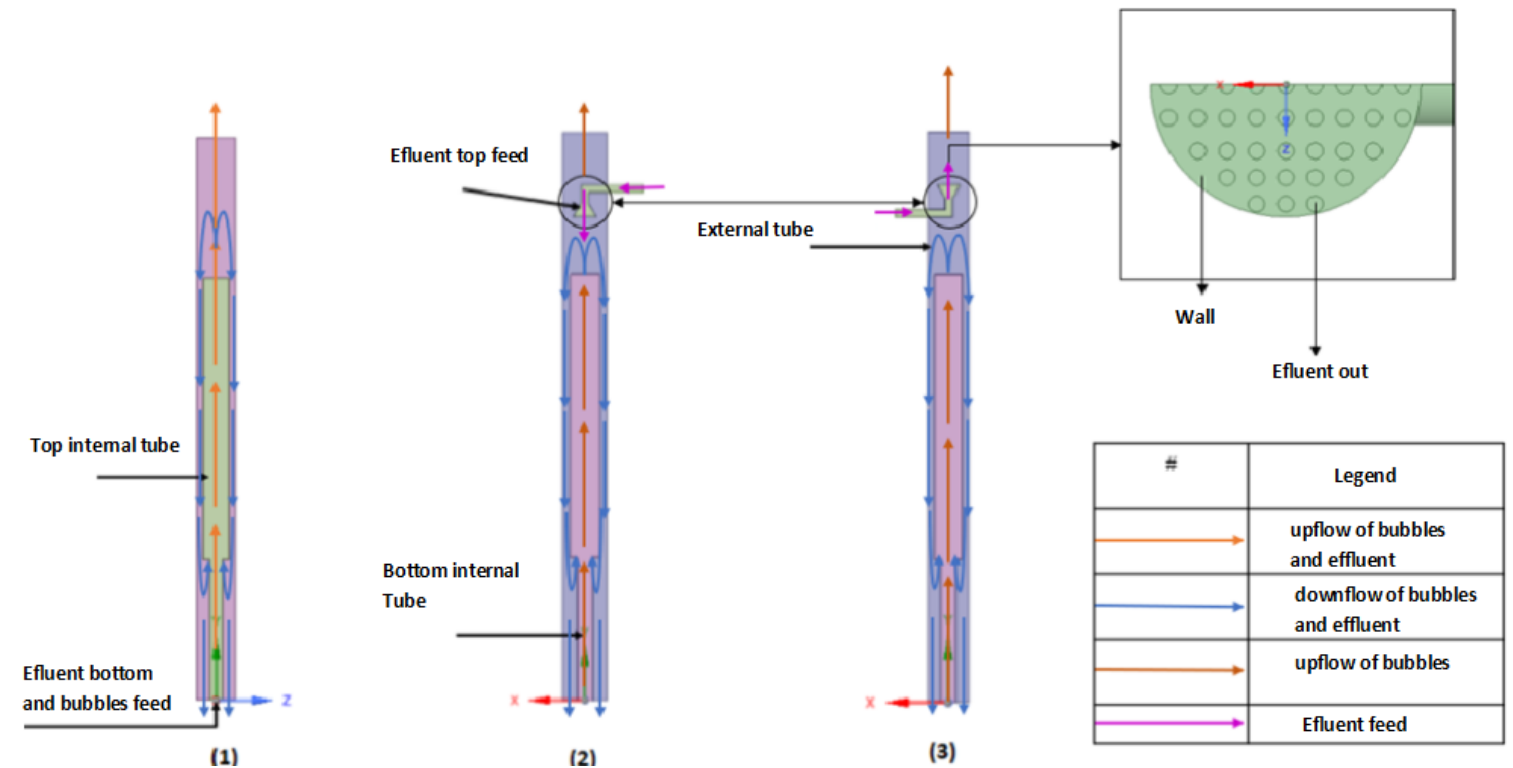

Figure 1. Internal fluid geometries and flows.

The three geometries differ in the effluent and bubble feed at the base of the column. Second and third geometries have a distinction in the effluent and bubble input, which are performed at different

Table 1. Column dimensions.

\begin{tabular}{clc}
\hline External tube & Dimension $[\mathrm{mm}]$ & 152.4 \\
& Length $[\mathrm{mm}]$ & 2000 \\
Base inner & Diameter $[\mathrm{mm}]$ & 50.8 \\
tube & Length $[\mathrm{mm}]$ & 500 \\
Top inner & Diameter $[\mathrm{mm}]$ & 101.6 \\
tube & Length $[\mathrm{mm}]$ & 1000 \\
\hline
\end{tabular}

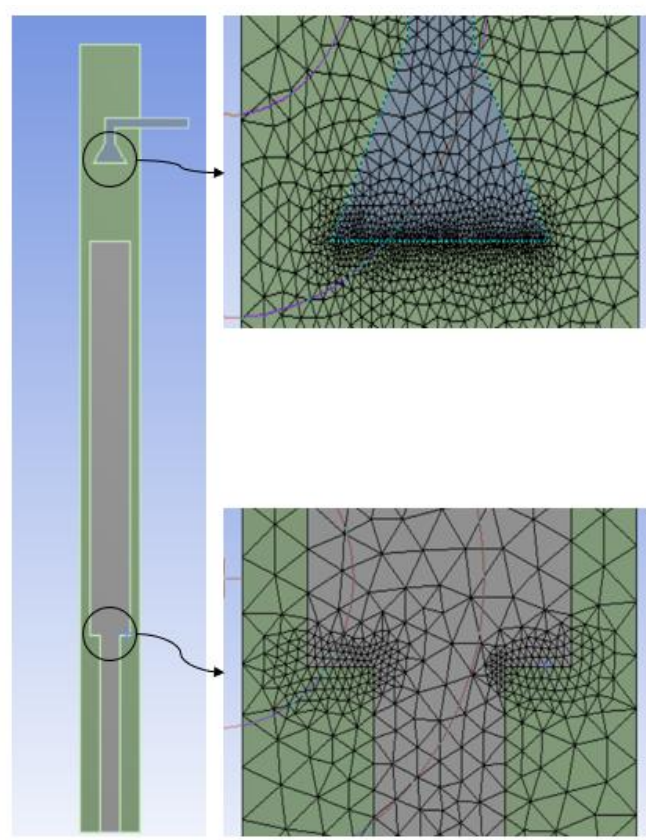

(2) locations, varying the positions at which the targeted effluent is located.

For this study, the second design will be described with the counter-current effluent feed. The third design will be described as co-current, and the configurations used in the studied columns can be observed in both Figure 1 and Table 1.

The effluent is fed into column (1) at the base, column (2) at $1800 \mathrm{~mm}$ from the base, and column (3) at $1700 \mathrm{~mm}$. In Figure 1, one can observe the flow of the fluids studied in the column.

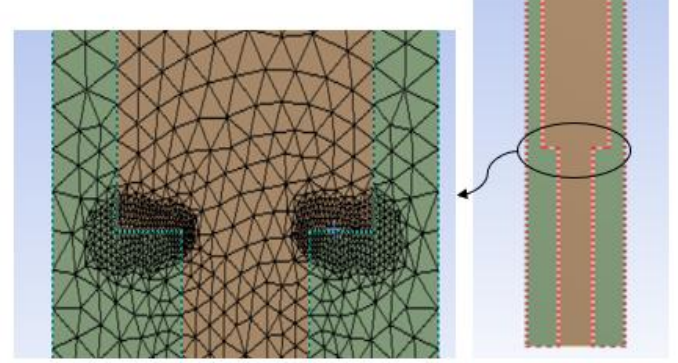

(1)

Figure 2. Mesh of geometry proposed. 
Table 2. Elements and nodes of mesh.

\begin{tabular}{cccc}
\hline Mesh & Column (1) & Column (2) & Column (3) \\
Elements & 221.655 & 212.857 & 276.972 \\
Nodes & 40.928 & 38.499 & 49.341 \\
\hline
\end{tabular}

Based on the geometry, an unstructured tetrahedral mesh was elaborated and used as the control volume. This shape allows a better adaptation to curved geometries. The meshes used can be observed in Figure 2 and their respective characteristics in Table 2 (Versteeg \& Malalasekera, 2007).

\subsection{Mathematical Model}

Considerations of study, models used, and methods of analysis of results used for simplifying hypotheses for the solution of the model:

- Stationary state;

- The effects of gravity are considered;

- Non-slip wall condition for continuous fluid;

- Free sliding on the wall for the scattered ones;

- Dispersed phase does not influence the velocity profile of the continuous phase;

- The continuous phase and the dispersed phase enter the column at the same rate;

- Constant properties of fluids;

- Constant bubble and droplet size;

- No chemical reactions.

The Eulerian-Eulerian formulation was used, considering the oil and air as dispersed phases in the continuous medium, water. The Euler-Euler formulation considers the global information of the existing phases, being expressed in a continuous form. The control volume must be determined correctly so that the profiles obtained based on this formulation are representative (Marinho, 2012).

\subsection{Equations for fluid domain}

Traditionally, mass and moment equations are designed to represent fluid-based systems, as long as their conditions are met (Bird et al., 2002). In fluid mechanics, the continuity equation is a consequence of the conservation of mass in a fluid flow. In a multiphase system with the Euler-Euler approach, we assume:

$$
\begin{gathered}
\frac{\partial \alpha_{i} \rho_{i}}{\partial t}+\nabla\left(\alpha_{i} \rho_{i} u_{i}\right)=0 \\
\frac{\partial\left(\alpha_{i} \rho_{i} u_{i}\right)}{\partial t}+\nabla\left(\alpha_{i} \rho_{i} u_{i} u_{i}\right)= \\
=-\alpha_{i} \nabla p+\nabla \alpha_{i}\left(\tau_{i}+\tau_{i}^{T}\right)+\alpha_{i} \rho_{i} g \\
+M_{i}
\end{gathered}
$$

Where $\alpha$, represents the volume fraction of phase $\mathrm{m}$; $M$ represents the terms of interfacial forces acting on the phases; and $\tau^{T}$ is the turbulent shear stress term that will be modeled from the two-equation turbulence model $k-\varepsilon$ (Sarhan et al., 2016).

\subsection{Turbulence model}

Term $\tau^{T}$ can be approximated by the Newton equation for shear stress, written by:

$$
\tau_{i}^{T}=\mu_{t}\left(\frac{\partial \bar{u}_{i}}{\partial x_{j}}+\frac{\partial \bar{u}_{j}}{\partial x_{i}}\right)-\frac{2}{3} k \delta_{i j}
$$

The $k-\varepsilon$ turbulence model assumes the existence of an isentropic turbulence, which can be modeled from two equations representing the turbulent kinetic energy and the dispersion of this energy, which are modeled from equations (4) to (6) (Zhang et al., 2017).

$$
\begin{aligned}
& \mu_{t}=C_{\mu} \rho \frac{k^{2}}{\varepsilon} \\
& \frac{\partial(\rho k)}{\partial t}+\frac{\partial\left(\rho k u_{i}\right)}{\partial x_{i}}= \\
& =\frac{\partial}{\partial x_{i}}\left[\left(\mu+\frac{\mu_{t}}{\sigma_{k}}\right) \frac{\partial k}{\partial x_{j}}\right]+G_{k}+G_{b}-\varepsilon \rho \\
& \frac{\partial(\rho \varepsilon)}{\partial t}+\frac{\partial\left(\rho \varepsilon u_{i}\right)}{\partial x_{i}}= \\
& =\frac{\partial}{\partial x_{i}}\left[\left(\mu+\frac{\mu_{t}}{\sigma_{\varepsilon}}\right) \frac{\partial \varepsilon}{\partial x_{j}}\right]+ \\
& +C_{1 \varepsilon} \rho \frac{\varepsilon}{k}\left(G_{k}+C_{3 \varepsilon} G_{b}\right)+C_{2 \varepsilon} \rho \frac{\varepsilon^{2}}{k}
\end{aligned}
$$




\subsection{Drag model}

The drag force is a measure of the equilibrium of relative velocity between phases, this force was modeling by equation (7).

$$
f_{d}=C_{d}\left(\frac{\pi}{4} d_{b}^{2}\right) \frac{\rho_{l}}{2}\left|\vec{u}_{g}-\vec{u}_{l}\right|\left(\overrightarrow{u_{g}}-\overrightarrow{u_{l}}\right)
$$

In Santos et al., 2007, the drag is the principal interfacial force in bubble columns, representing a good approximation. The drag model used in this work is the model proposed by Grace.

This model proposed establishes a relationship between flow regime and bubble shape by mapping particle Reynolds and Eötvös numbers for different systems with value of the Morton number, which for bubble column are defined from equations (8) to (10) (Riera-Ortiz et al. 2012).

$$
\begin{aligned}
& R e_{b}=\frac{\rho_{l} d_{b}\left|u_{b}-u_{l}\right|}{\mu_{l}} \\
& E o=\frac{\rho_{l} d_{b}^{2}}{\sigma} \\
& M=\frac{g \mu_{l}^{4}}{\rho_{l} \sigma^{3}}
\end{aligned}
$$

Grace correlation evaluates the drag coefficient by analyzing the different shapes of the bubble. When the Reynolds number was low, Equation (8), one can estimate that this coefficient is similar to a spherical shape, and that this form will change according to the increase in Reynolds number, which is modeled from equations (11) to (14) (Lote et al., 2018).

$$
\begin{aligned}
& C_{d}=\max \left[\min \left(C_{d, \text { ellipse }}, C_{d, \text { cap }}\right) C_{d, \text { sphere }}\right. \\
& C_{d, \text { sphere }}=\frac{24}{\operatorname{Re}_{b}}\left(1+0.1 \operatorname{Re}_{b}^{0.75}\right) \\
& 0<\operatorname{Re}_{b}<1000
\end{aligned}
$$

$$
\begin{aligned}
& C_{d, \text { ellipse }}=\frac{4}{3} \frac{d_{p}\left(\rho_{l}-\rho_{g}\right)}{U_{T} \rho_{l}} \\
& 1000<R e_{b}<100000 \\
& C_{d, \text { cap }}=\frac{72}{R e_{b}} \\
& R e_{b}>100000
\end{aligned}
$$

Where $\mathrm{Ut}$ is the terminal velocity of the bubbles and it is given by:

$$
\begin{aligned}
& U_{t}=\frac{\mu_{l}}{\rho_{l} d_{p}} M^{-0.149}(J-0.857) \\
& J=\left\{\begin{aligned}
94 H^{0.751}, & 2<H<59.3 \\
3.42 H^{0.441}, & x \geq 59.3
\end{aligned}\right. \\
& H=\frac{4}{3} E o M^{-0149}\left(\frac{\mu_{l}}{0.0009}\right)
\end{aligned}
$$

\subsection{Boundary conditions and physical properties of materials}

Tables 3 to 5 list the physical properties of the fluids, the initial condition, and the boundary condition of the analyzed control volume

The initial conditions of the test will be the entire column filled with water and stagnant flow. Volumetric fraction of water and their mean velocity are equal to 1 and 0 , respectively.

The boundary conditions applied to the columns

\begin{tabular}{|c|c|c|c|c|c|}
\hline Material & $\begin{array}{c}\text { Viscosity } \\
\text { [Pa.s] }\end{array}$ & $\begin{array}{l}\text { Density } \\
{\left[\mathrm{kg} / \mathrm{m}^{3}\right]}\end{array}$ & ${ }^{\circ} \mathrm{API}$ & $\begin{array}{l}\text { Superficial tension } \\
\text { Air|Water }[\mathrm{N} / \mathrm{m}]\end{array}$ & $\begin{array}{c}\text { Superficial tension } \\
\text { Water|Oil [N/m] }\end{array}$ \\
\hline Air & 0.000018 & 1.185 & 0 & \multirow{2}{*}{0.0720} & - \\
\hline Water & 0.000889 & 997.000 & 0 & & \multirow{2}{*}{0.0307} \\
\hline Oil & 0.050450 & 878.033 & 29.5 & - & \\
\hline
\end{tabular}
were considered so that all columns had similar volumetric flow rates, making this input factor not a differential for this analysis, as well as the initial volumetric fraction of the column supply currents.

\subsection{Case study}

The computational analysis for this stage of the study consists of the evaluation of the effluent feed positioning in the column, thus, maintaining initial and boundary conditions similar to all analyses. This will ensure that the only preponderant factor of variation in concentrations effluent is the design involved in the analysis.

Table 3. Physical properties of used materials. 
Table 4. Volumetric fractions in column entries.

\begin{tabular}{ccccc}
\hline \multirow{2}{*}{ column } & Feed & \multicolumn{2}{c}{ Volumetric Fraction } & Air \\
\hline Column (1) & Bottom & 0.001 & Water & 0.0600 \\
Column (2) e (3) & Top & 0.001 & 0.9989 & 0 \\
& Bottom & 0 & 0.9400 & 0.0600 \\
\hline
\end{tabular}

Table 5. Boundary conditions of the studied columns.

\begin{tabular}{|c|c|c|c|}
\hline \multicolumn{4}{|c|}{$\ln$} \\
\hline Position & Column (1) & Column (2) & Column (3) \\
\hline Top & $0[\mathrm{~m} / \mathrm{s}]$ & $0.01[\mathrm{~m} / \mathrm{s}]$ & $0.01[\mathrm{~m} / \mathrm{s}]$ \\
\hline Bottom & $0.0225[\mathrm{~m} / \mathrm{s}]$ & $0.02[\mathrm{~m} / \mathrm{s}]$ & $0.02[\mathrm{~m} / \mathrm{s}]$ \\
\hline \multicolumn{4}{|c|}{ Out } \\
\hline Top & 1 [atm] & 1 [atm] & 1 [atm] \\
\hline Bottom & $0,004[\mathrm{~m} / \mathrm{s}]$ & $0.004[\mathrm{~m} / \mathrm{s}]$ & $0.004[\mathrm{~m} / \mathrm{s}]$ \\
\hline
\end{tabular}

A removal efficiency metric was used for the analysis of the results. Its evaluation consisted on the differences between oil concentration in the feed, in ppm, and oil concentration in the base of the column, in ppm, according to equation (18):

$$
\eta=\frac{\left(C_{i n}-C_{o}\right)}{C_{i n}} * 100 \%
$$

\section{RESULTS AND DISCUSSIONS}

In Figure 3, it is possible to observe the oil volume fraction profiles distributed in the columns analyzed. As the column fluid inlet and outlet contour conditions were kept constant in the three situations analyzed, the variations observed in these profiles were generated by the hydrodynamic behavior between the phases.
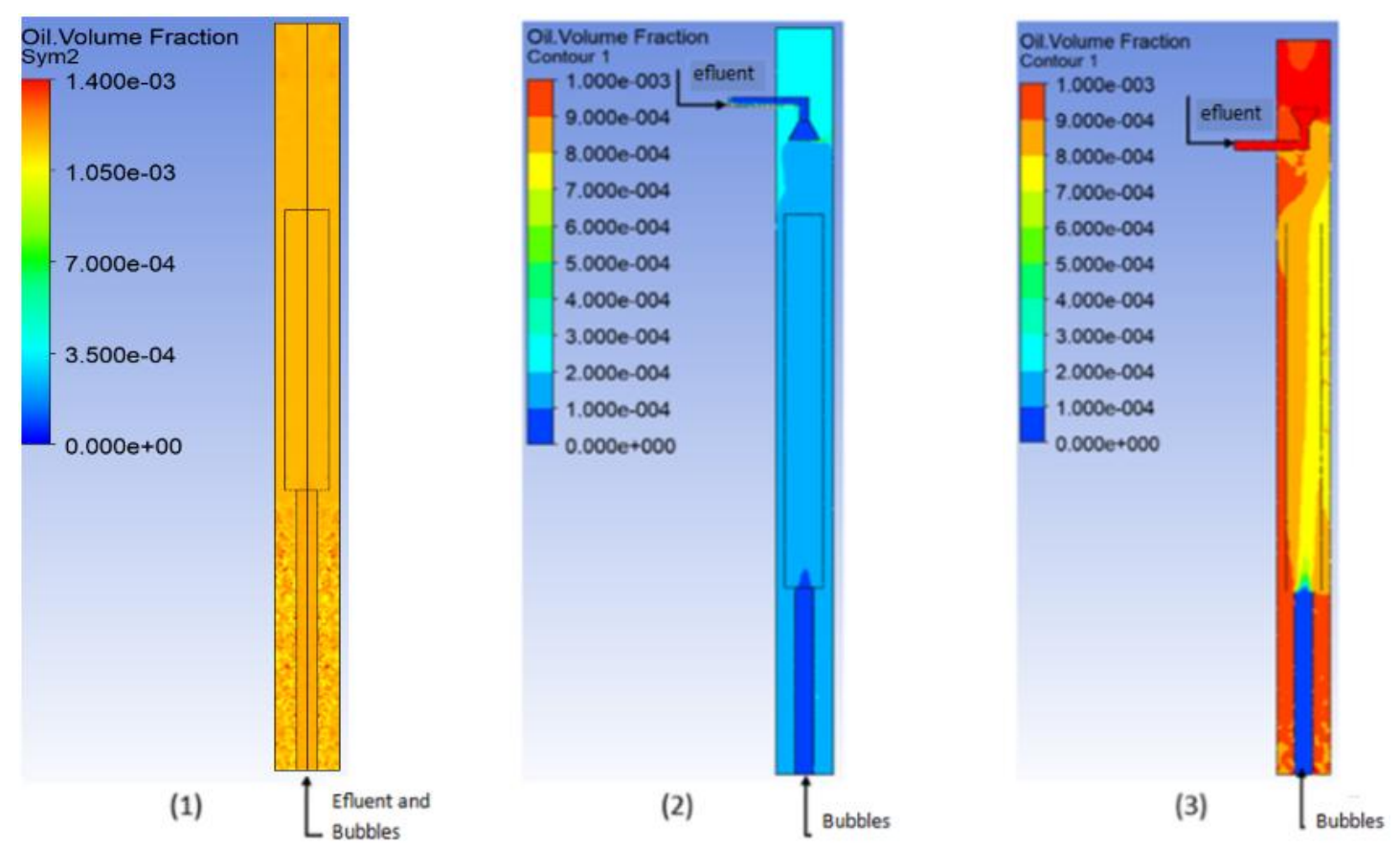

Figure 3. Volumetric fraction of oil in the studied columns. 


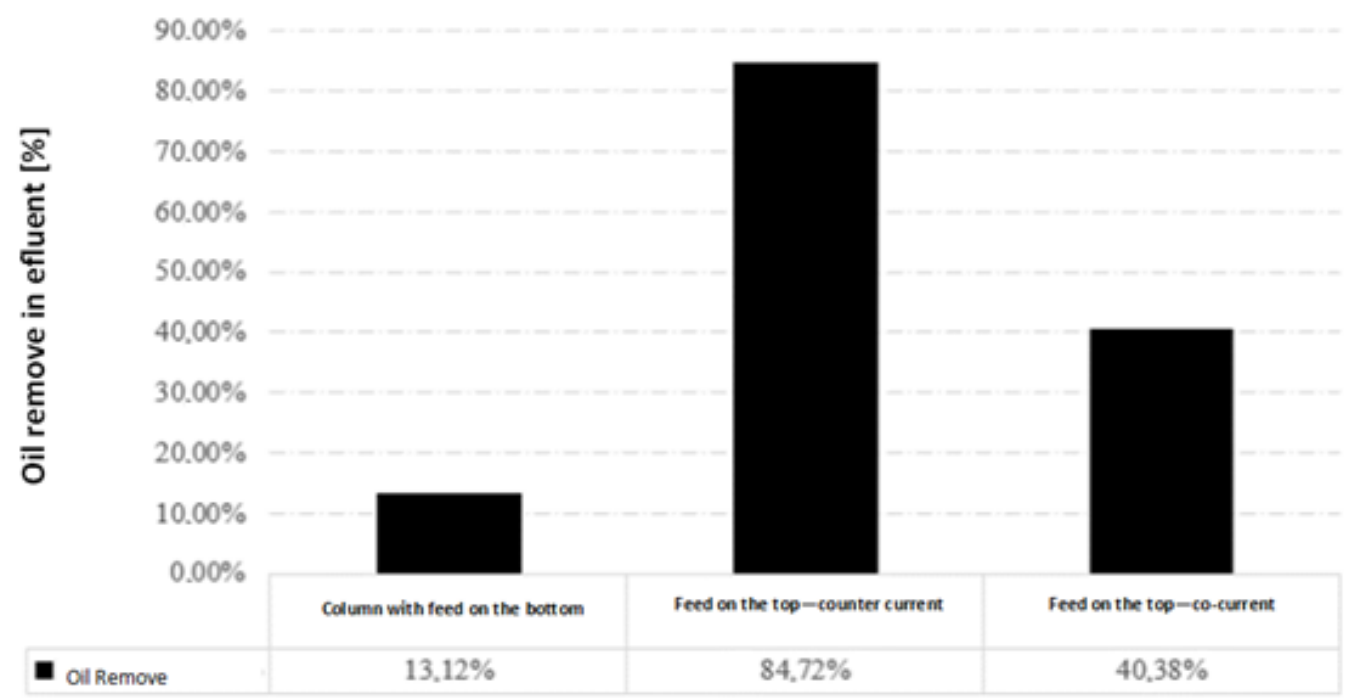

Figure 4. Separation efficiency of the studied columns.

It is noteworthy that, due to the visualization of the oil volume fractions, the chosen range of $0,-10$, and -3 allowed a better analysis of the oil distribution in the columns. However, column (1) has a high effluent concentration when compared with the other columns studied. Figure 4, shows that column (1) has an efficiency almost eight times lower than column (2), which presented the best result (84.72\%).

Observing Figure 4, one can visualize that there are large differences between the oil volume fraction profiles, with a low separation in column (1), observed by its homogeneous color and without difference in concentration points, while column designs (2) and (3) show a gradient of volumetric oil fractions across the whole column body.

From the analysis of Figure 4 one can infer that column (2) - countercurrent - has a design that allows a better separation efficiency, $84.72 \%$ of the oil that is fed into the column is removed by the process. Studies by Marinho (2015) and Qi et al. (2013) presented removals of $83 \%$ and $89.3 \%$, respectively, supporting that the profile analyzed is consistent with reality.

The feeding location has a significant influence on the efficiency of the column, with emphasis on column (2). For the column design (1), one can observe that the contact between the phases is small, since both effluent and air enter the column from the same place. Differently, the other two studied designs allowed efficiencies greater than 6 and 3 times, respectively, if compared to column (1).

The phenomena generated by the column recirculation in the recirculation zone, which is in the region in the connection between the column internal tubes, can impair the adhesion process between the bubbles and the oil droplets, as noted in (Matiolo \& Rubio, 2003). Hydrodynamic factors such as shear forces may influence positively or negatively on phase adhesion.

In Figure 5, one can observe the oil velocity in the recirculation region, knowing that the velocity profiles influence the shear stress, thus, inducing or decreasing adhesion between air and oil particles.

Analyzing Figures 4 and 5, we can infer from the relationship established by Matiolo and Rubio (2003) that the high turbulence of the oil in column (1) was one of the factors that led to its low removal efficiency. This chaotic velocity gradient generated does not allow particles to have enough contact time to adhere to the bubbles.

The analysis of column (3) shows that particles do not have enough force for the contact between them to allow an adhesion. The design of column (2) allows a balance between the two profiles studied, being reflected in the removal efficiency of Figure 4. 


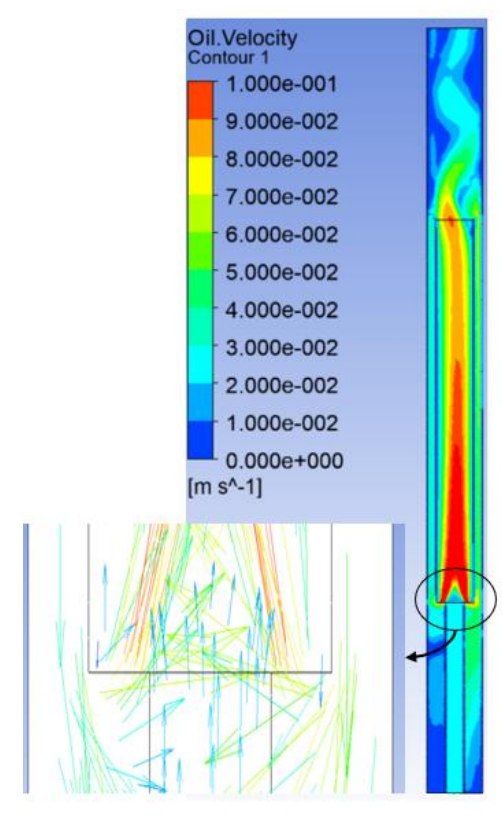

(1)

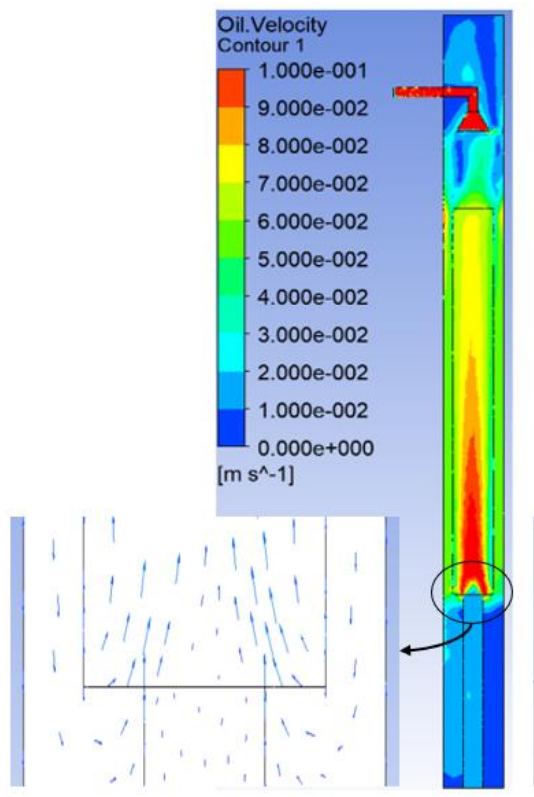

(2)

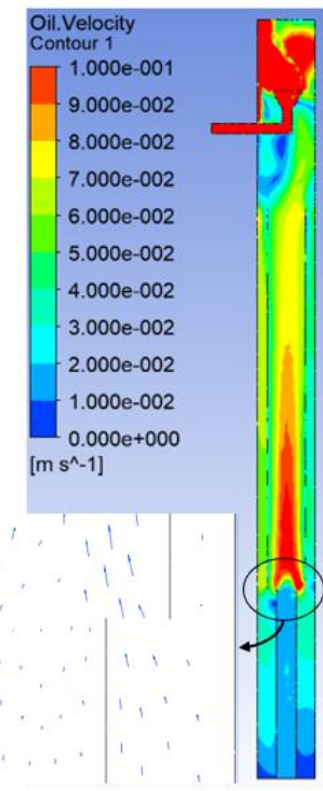

(3)

Figure 5. Oil velocity profile in column recirculation region.

The countercurrent profile of column (2) also allows a better contact between bubbles and oil droplets. Column design (3) - co-current presented an increased advantage, that is, more than twice the efficiency of oil removal.

Most authors in the literature use countercurrent designs. According to Nagase et al. (1998), this profile allows a better contact between ascending and descending phases, allowing a high probability of colliding and adhering to each other.

\section{CONCLUSIONS}

Based on the results obtained, one can infer that keeping the effluent feeds separate from the bubble feed allows better efficiency. Based on the literature, one can see that the results obtained by column (2) - which was the best profile analyzed in the study - do not differ from results presented by other authors such as Marinho (2015), which presented $83 \%$ oil removal.

The mathematical model described in this paper obtained a good accuracy with the data observed in the experiments, showing a relative error of $2.09 \%$ if compared to the work of Marinho (2015), and $5.10 \%$ if compared to the work of Qi et al. (2013).
Both results were contrasted with the results from column (2).

Another factor that can be observed is the influence of effluent feed placement. According to column (2), the countercurrent format allowed a better contact between the phases and, consequently, a higher probability of these phases to adhere to each other and be removed from the column by the coalescence of air bubbles.

This factor was also observed in the other columns, even though it was more perceptive in column (1), which shows that the effluent did not have a good contact with the high turbulence generated in the recirculation zone, as well as in column (3), that did not have good contact. Low turbulence was responsible for the promotion of better contact.

The turbulence in the recirculation region decreased the probability of oil droplets adhesion in air bubbles. The recirculation allows part of this oil that had not been adhered by the air mattress to be captured by the rising air flow, thereby allowing more oil droplets to be captured. Results of columns (1) and (3) show obtained efficiencies of $13.12 \%$ and $40.38 \%$, respectively. 


\section{NOMENCLATURE}

Latin letters:

C Oil concentration

$\mathrm{C} \mu \quad$ Model k- $\varepsilon$ constant

$\mathrm{C}_{1 \varepsilon} \quad$ Model of dispersion of kinect energy constant

$\mathrm{C}_{2 \varepsilon} \quad$ Model of dispersion of kinect energy constant

$\mathrm{C}_{3 \varepsilon} \quad$ Model of dispersion of kinect energy constant

$C_{d} \quad$ Drag coefficient

$d_{b} \quad$ Diameter of bubble

g Gravity acceleration

$\mathrm{G}_{\mathrm{k}} \quad$ Model of turbulent of kinect energy constant

$\mathrm{G}_{\mathrm{b}} \quad$ Model of turbulent of kinect energy constant

k Turbulent kinect energy

$\mathrm{M}_{\mathrm{i}} \quad$ Interfacial forces on phase $\mathrm{i}$

$p$ Pressure

$u_{i} \quad$ Velocity of i phase

$\mathrm{U}_{\mathrm{T}} \quad$ Terminal velocity

$x_{i} \quad$ Volume fraction of i phase

$\mathrm{t}$ Time

\section{Greek letters:}

$\alpha_{i} \quad$ Volume fraction of i phase

$\mu \quad$ Dynamic viscosity

$\mu_{t} \quad$ Turbulent dynamic viscosity

$\mu_{l} \quad$ Dynamic viscosity in liquid phase

$\varepsilon \quad$ Dispersion of kinetic energy

$\rho$ Density

$\rho_{l} \quad$ Density in liquid phase

$\sigma \quad$ Superficial tension

$\sigma_{\varepsilon} \quad$ Model of dispersion of kinetic energy constant

$\sigma_{k} \quad$ Model of turbulent of Kinect energy constant

$\tau \quad$ Shear stresses

$\tau_{i}^{t} \quad$ Turbulent Reynolds stresses of $i$ phase

$\delta_{i j} \quad K r o n e c k e r ' s$ delta

\section{Symbols:}

$\nabla \quad$ Gradient operator

\section{REFERENCES}

Ammar, S. H.; Akbar, A. S. Oilfield produced water treatment in internal-loop airlift reactor using electrocoagulation/flotation technique. Chinese journal of chemical engineering, v. 26(4), p. 879885, 2018. https://doi.org/10.1016/j.cjche.2017.07.020

Bird, R. B.; Stewart, W. E.; Lightfoot, E. N. Fenômenos de transporte. $2^{\circ}$ ed. Rio de Janeiro: LTC, 2002. (in Portuguese)

Gu, X.; Chiang, S.-H. A novel flotation column for oily water cleanup. Separation and Purification Technology, v. 16(3), p. 193-203, 1999. https://doi.org/10.1016/S1383-5866(99)00004-0

He, D.; Ding, F.; Hu, H.; Chiang, S. A multiple-loop flotation column for wastewater treatment. Separations Technology, v. 5(3), p. 133-138, 1995. https://doi.org/10.1016/0956-9618(94)00118-C

$\mathrm{m}^{2} / \mathrm{s}^{2}$

$\mathrm{N} / \mathrm{m}^{3}$

$\mathrm{Pa}$

$\mathrm{m} / \mathrm{s}$

$\mathrm{m} / \mathrm{s}$

$\mathrm{m}$

$\mathrm{s}$

Lote, D. A.; Vinod, V.; Patwardhan, A. W. Comparison of models for drag and non-drag forces for gas-liquid two-phase bubbly flow. Multiphase Science and Technology, v. 30(01), 2018. https://doi.org/10.1615/MultScienTechn.2018025983

Marinho, C. S. Processo de flotação com recirculação interna aplicado à separação petróleo-água. Dissertação de Mestrado. Programa de Pós-Graduação em Engenharia Química, N.s $/ \mathrm{m}^{2}$ N.s $/ \mathrm{m}^{2}$ N.s $/ \mathrm{m}^{2}$ $\mathrm{m}^{2} / \mathrm{s}^{2}$ $\mathrm{kg} / \mathrm{m}^{3}$ $\mathrm{kg} / \mathrm{m}^{3}$

$\mathrm{N} / \mathrm{m}$ $\mathrm{N} / \mathrm{m}$

$\mathrm{N} / \mathrm{m}$

$\mathrm{kg} /\left(\mathrm{m} \cdot \mathrm{s}^{2}\right)$ $\mathrm{kg} /\left(\mathrm{m} \cdot \mathrm{s}^{2}\right)$ Universidade Federal de Alagoas, 2015. (in Portuguese)

Marinho, J. L. G. Escoamento anular isotérmico de óleos pesados e água em bifurcações angulares: modelagem e simulação, Tese de Doutorado. Programa de Pós-Graduação em Engenharia Química, Universidade Federal de Campina Grande, 2012. (in Portuguese)

Matiolo, E. D. M. E.; Rubio, J. Flotação avançada para o tratamento e reaproveitamento de águas poluídas. XIX PRÊMIO JOVEM CIENTISTA-ÁGUAFONTE DA VIDA, Porto Alegre, 2003. (in Portuguese)

Nagase, H.; Eguchi, K.; Yoshihara, K.-I.; Hirata, K.; Miyamoto, K. Improvement of micro algal nox removal in bubble column and airlift reactors. Journal of Fermentation and Bioengineering, $v$. 86(4), p. 421-423, 1998.

https://doi.org/10.1016/S0922-338X(99)89018-7 
Qi, W.-K.; Yu, Z.-C.; Liu, Y.-Y.; Li, Y.-Y. Removal of emulsion oil from oilfield asp wastewater by internal circulation flotation and kinetic models. Chemical Engineering Science, v. 91, p. 122-129, 2013. https://doi.org/10.1016/i.ces.2013.01.020

Rajak, V.; Relish, K.; Kumar, S.; Mandal, A. Mechanism and kinetics of separation of oil from oil-in-water emulsion by air flotation. Petroleum Science and Technology, v. 33(23-24), p. 18611868, 2015.

https://doi.org/10.1080/10916466.2015.1108987

Riera-Ortiz, J; Zeppieri, S; Rojas-Solórzano, L; Derjani, S. Evaluation of interphase drag models for the determination of gas hold-up of an air-water system in a spouted bed using CFD. Journal of Computational Methods in Sciences and Engineering, v.12, p. 269-281, 2012.

https://doi.org/10.1080/10916466.2015.1108987

Sarhan, A.; Naser, J.; Brooks, G. CFD simulation on influence of suspended solid particles on bubbles' coalescence rate in flotation cell. International Journal of Mineral Processing, v. 146, p. 54-64, 2016.

https://doi.org/10.1016/i.minpro.2015.11.014
Thompson, J. P. Passando a Limpo: A Flotação por ar dissolvido no tratamento de efluentes industriais. Jundiai: Paco Editorial, 2015. (In Portuguese)

Versteeg, H. K.; Malalasekera, W. An introduction to computational fluid dynamics: The finite volume method. Porto Alegre: Pearson Education, 2007.

Yu, L.; Han, M.; He, F. A review of treating oily wastewater. Arabian Journal of Chemistry, v. 10, p. S1913-S1922, 2017.

https://doi.org/10.1016/i.arabjc.2013.07.020

Zhang, M.; Li, T.; Wang, G. A CFD study of the flow characteristics in a packed flotation column: Implications for flotation recovery improvement. International Journal of Mineral Processing, v. 159, p. 60-68, 2017. https://doi.org/10.1016/i.minpro.2017.01.004 